\title{
$\mathrm{CAD}$ 프로그램을 활용한 기하학 문양의 직물 디자인 종광설계
}

\author{
김수미 \\ 숙명여자대학교 의류학과
}

\section{Weave Draft Designs Influenced by Geometric Patterns using a CAD Program}

\author{
Su-Mi Kim ${ }^{\dagger}$ \\ Dept. of Clothing \& Textiles, Sookmyung Women's University; Seoul, Korea
}

\begin{abstract}
In textile industry, needs for various weave drafts have been increased to produce high qualified textile goods. One of disadvantages of traditional textile industry was spending time and money on manual sampling. Nowadays, however, weave draft design and sampling using CAD programs reduce these consumption efficiently. Therefore, this study aimed to provide high qualified woven fabrics by weave draft designs influenced by geometric patterns. First, We analyzed geometric patterns, except for dot, stripe, and checks, in fashion collections from 2009 to $2014 \mathrm{~S} / \mathrm{S}$. Then, based on these analyses, design concepts were decided. Third, weave drafts influenced by geometric patterns were designed with weave CAD program, TEX PRO 10.0 by Youngwoo CNI inc. Forth, We simulated fabrics woven by new drafts using CAD programs, depending on fibers, yarns, density of woven, colors, and finishes. Unclassified geometric patterns would be expressed by small size patterns that influenced by retro moods, square patterns with various color variation, zigzag lines, and pieces of puzzles. Three design concepts were decided as greenness, neoclassic, and romantic chic. Thus, geometric patterns for printing were created as drafts for general looms, and one repeat of each draft were provided. According to the design concepts, we designed 13 fabrics with 4 geometric patterns weaving drafts. All Drafts were designed with CAD programs. Finally, same drafts were simulated as woven fabrics for both S/S and F/W seasons by changing each element, such as fiber, yarns, density, colors, and finishes.
\end{abstract}

Key words: weaving $\operatorname{draft}($ 종광설계), geometric pattern(기하학 문양), fashion collection(패션 컬랙션), general loom( 일반직기), TEX PRO 10.0, CAD programs(텍스 프로 10.0)

1. 서

최근 국내 섬유산업 중 직물제직과 같은 생산 산업은 개발 도상국의 추격으로 경쟁력을 상실하고 있으므로 직물제직 산업 이 선진국형의 구조로 전환되기 위해서는 품질향상과 고부가가 치화가 필요하다. 따라서 선진국과의 경쟁력을 확보하기 위해 서 무엇보다 중요한 것은 첨단 신소재의 개발, 염색, 가공 기 술개발을 통한 차별화 소재의 개발 및 직물 디자인의 고급화에 있다. 그 중 직물의 디자인 창출은 부가가치를 높이는데 있어 중요한 역할을 담당한다. 고부가가치의 직물이 만들어지기 위 해서는 선염과 날염, 자수 및 직물조직 종광설계 등 다양한 영 역에서 직물 디자인이 발전되어야 한다. 선염과 날염, 자수 등 은 이미 만들어진 직 - 편물을 사용하여 진행되고 있어 비교적 빠르게 트랜드를 반영할 수 있는 장점이 있다. 그러나 직물의 조직변화에 따른 입체적인 직물은 완제품 제직 전에 종광설계

$\dagger$ Corresponding author; Su-Mi Kim

Tel. +82-2-710-9462, Fax. +82-2-710-9462

E-mail: k9932063@sm.ac.kr
및 실의 종류, 굵기 및 색상에 따른 예비샘플 작업이 수작업으 로 진행되기 때문에 많은 시간과 경비가 드는 단점이 있다. 이 러한 단점을 보완하기 위해 최근 직물조직의 종광디자인 설계 및 예비 샘플 작업에 적용되고 있는 $\mathrm{CAD}$ 프로그램은 디자인 의 수정, 변경, 저장, 관리 등이 효율적이며, 빠르고 간편하게 디자인 작업을 수행할 수 있기 때문에, 직물 디자인에서 그 중 요성이 부각되고 있다. 따라서 $\mathrm{CAD}$ 프로그램을 통한 디자인 작업은 직물 디자인 산업분야에 있어 매우 보편화되고, 이와 관 련된 연구도 점차 늘어나고 있다(Kim, 2008). 이러한 직물의 종광설계 또는 패턴설계 등으로 지금까지 보고된 선행연구를 살펴보면 다음과 같다.

직물의 조직패턴에 관련된 선행연구로 Lee and Park(2009) 은 2009, 2010년도 F/W 인테리어 트렌드를 중심으로 기하학적 문양을 모티브로 한 커튼 직물 디자인 연구에서 커튼 직물은 문양 계획과 색채계획이 그 어떤 요소보다 우선하며, 직물조직 의 짜임 뿐 아니라 다양한 디자인 기법을 활용하여 여러 가지 디자인을 창출할 수 있음을 제시하였다. Lee(2008)는 2008, 2009년 S/S 트렌드의 테마에 따른 컬러, 소재를 분석하고 선 면에 의한 커튼 직물 디자인에서 직물의 느낌을 다양화하기 위 
해 색, 조직의 밀도, 실의 고유특성, 자수나 스티치 등 다양한 기법 활용을 통한 직물 디자인 활용방안을 연구하였다. 특히 직 물 디자인 분야에서 직물조직 패턴설계 부분이 가장 먼저 $\mathrm{CAD}$ 프로그램을 활용하여 왔다. $\mathrm{CAD}$ 프로그램을 이용한 직 물설계는 $\mathrm{CAD}$ 프로그램에 내장된 종광 패턴을 이용하여 변형 시킬 수 있으며, 또한 새로운 종광패턴을 설계할 수도 있다. $\mathrm{CAD}$ 프로그램을 이용한 직물설계는 설계된 조직의 종류, 조직 의 반복, 경 - 위사의 밀도, 사용되는 실의 색상 외에 실의 종 류, 꼬임, 굵기 등을 제직 전에 완벽하게 시연해 볼 수 있는 장점이 있다(Han, 2000; Jenny, 2008; Kim, 2008).

컴퓨터를 활용한 직물조직 패턴설계와 관련된 선행연구로 $\mathrm{Oh}$ and $\operatorname{Kim}(2008)$ 은 1960년대 복식에 많은 영향을 준 팝아트와 옵아트의 조형요소의 특징을 현대패션에 적용하여 텍스타일 $\mathrm{CAD}$ 에 의한 다양한 형태의 패턴 디자인 시뮬레이션과 새로운 개념의 텍스타일 디자인의 가능성을 제시하였고, Choi(2010)는 식물의 조형적인 특성을 관찰하여 컴퓨터 위빙프로그램을 활용 한 직물 설계를 위해 다양한 스레딩을 사용하여 직물의 질감표 현 효과를 높인 패턴 제작에 대하여 보고하였다. 또한 $\mathrm{Kim}$ and $\mathrm{Do}(1998)$ 는 전통적인 체크패턴에 관해 분석하고 위빙프로 그램을 사용하여 체크무늬의 독특한 아름다움과 현대적인 색감 각을 조화시켜 새로운 체크문양을 제시하였다. Choi and $\operatorname{Kim}(2009)$ 은 실제의 직물과 $\mathrm{CAD}$ 프로그램에 의해 시뮬레이션 된 직물과의 유사성을 분석하기 위해 화상분석 방법을 적용하 여 향후 텍스타일 $\mathrm{CAD}$ 프로그램에서 보완되어야 할 내용을 제시하였다.

이상 선행연구를 살펴본 결과, 현재까지 $\mathrm{CAD}$ 프로그램을 이 용한 직물의 패턴 디자인에 관한 연구는 직물에 나타난 문양패 턴을 분석하거나 컴퓨터 그래픽을 사용하여 날염으로 표현할 수 있는 문양패턴을 디자인하는 방법 등에 집중되어 있으며, 기 본조직을 바탕으로 스트라이프 또는 체크와 같이 경 - 위사의 색사 배열에 따라 다양하게 표현되는 직물제직으로 집중되어 있다. 그러나 섬유산업에 있어 큰 비중을 차지하는 직물제직에 있어 일반직기는 가장 기본이 되는 3 원 조직 위주로 직물을 제 직하고, 조직에 의한 무늬직물 제직은 주로 도비 직기 또는 자 카드 직기로 제직하므로 직물 생산 시 가격 상승 및 생산 시 간이 길어지게 된다. 따라서 일반직기를 사용하여 생산에 있어 효율적이면서 다양한 종광디자인에 의한 문양직물을 생산하는 것은 차별화된 직물생산에 경쟁력을 향상시킬 수 있을 것이며, 색상 배열에 의해 간단하게 표현되는 스트라이프, 체크보다는 그래픽 요소를 갖춘 기하학적 무늬 직물의 제직이 현대인의 높 아가는 미의식과 새롭고 독창적인 디자인에 대한 옥구에 부응 하면서 산업적으로 고부가가치를 창출할 수 있는 직물의 디자 인 개발에 기여할 것으로 판단된다.

따라서 본 연구의 목적은 최근 5년간 세계 4대 컬렉션 $(\mathrm{New}$ York, Paris, Milan, London)에 나타난 날염 및 선염 직물의 문양 중 가장 빈도수가 높은 기하학적 요소를 직조 $\mathrm{CAD}$ 프로 그램을 활용하여 반영한 직조 디자인을 제시하는데 있다. 이를
통해 빠르게 변화하는 패션 트렌드에 다양하게 적용될 수 있도 록 다품종 소량생산의 고부가가치 패션소재 생산에 기여할 수 있을 것으로 기대된다.

연구내용은 직물제직에 있어 일반직기에 적용 가능한 기하 학 종광디자인을 설계하기 위하여 첫째, 2009년 S/S 시즌부터 2014년 S/S 시즌까지 New York, Paris, Milan, London의 패 션 컬렉션을 토대로 도트, 체크, 스트라이프를 제외한 기하학 문양의 특징을 분석하였다. 둘째, (주)영우의 TexPro 프로그램 중 Weave 프로그램을 이용하여 분석한 기하학 문양을 토대로 일반직기에 적용 가능한 종광디자인을 설계하고, 원사의 종류, 꼬임수, 꼬임방향 및 굵기 등을 $\mathrm{S} / \mathrm{S}$ 시즌과 $\mathrm{F} / \mathrm{W}$ 시즌에 맞도 록 실을 설계하였다, 또한 직물 제직 시, 경위사의 색상 및 밀 도 변화, 표면가공(기모가공)여부 등을 변화시켜 $\mathrm{S} / \mathrm{S}$ 시즌과 $\mathrm{F} /$ $\mathrm{W}$ 시즌용 직물의 디자인을 제안하였다.

\section{2. 이론적 배경}

\section{1. 기하학의 개념}

기하학을 의미하는 geometry는 그리스어의 geometrein으로부 터 유래되었다. Geometrein은 ‘땅, 토지'를 의미하는 geo와 ‘측정 하다'를 의미하는 metrein이 합쳐진 것으로, 고대 이집트인의 토 지 측량에 의한 도형의 연구를 기하학의 기원이라고 보고 있다.

기하학적 형태는 인류의 시작과 더불어 끊임없이 연구되어 온 예술의 소재이다. 예술작품에 기하학적 형태가 등장한 것은 원시시대부터이며, 원시인들의 의식적, 무의식적 활동의 소산으 로 시작된 추상미술이 고대 그리스의 철학적 사유를 거쳐 기하 학으로 발전하게 되면서 기하학적 형태는 비례와 질서, 크기의 개념으로 예술작품에 도입되었고(Lee \& Ryu, 2003) 근대 디자 인사의 흐름 속에 변천, 발전되어오면서 시대적, 지역적으로 다 양한 양상을 보여 왔으며 삶의 보편적이고 포괄적인 형태를 나 타내고 있다. 텍스타일 디자인 분야에서 기하학적 형태는 20 년 대 큐비즘의 영향을 받은 소니아 들로네(Sonia Delaunary, 1885 1979)의 직물, 60 년대 몬드리안의 회화를 차용한 이브 생 로랑(Yves Saint Laurent, 1936 2008)의 의상에 많이 나타났다. 그 외에도 시대적 예술양식이나 예술사조와 그 맥을 같이 하여, 새로운 발상을 위해 기하학적 형태를 응용한 여러 가지 방법이 패션디자인에 시도되고 있다(Yang et al., 2008).

\section{2. 기하학 문양}

현대의 패션은 시대적 상황의 영향과 미적 가치를 중요시 하 므로 시대를 대표하는 관념과 가치관이 실질적이고 가시적인 상징으로 여겨진다. 특히 60 년대 패션 디자인은 시각적 미술인 옵티컬 아트를 수용하였다. 옵티컬 아트의 영향을 받은 기하학 문양은 왜곡된 점의 형태로 음양 효과나 평면적인 부분에 보다 부드러운 율동미나 곡선미를 나타낼 수 있으며, 방사선이나 소 용돌이를 나타내는 문양은 집중효과가 있어서 쉽게 눈에 띤다. 특히 팽창과 수축 문양은 시선을 즐겁게 해주는 매력이 있어 
시선을 분산시킨다. 이와 같이 옵티컬 아트 문양의 형태 조형 요소인 점 - 선 - 면이 지니는 시각적 특성은 단순하고도 간결 한 흑-백의 대비와 색채착시이며, 직선 또는 사각면의 형태는 현대적 세련미를 더해주며, 문양 자체가 지니는 운동감이나 입 체감, 다양성에 의해 단순한 시각적인 아름다움을 주고 있다 (Lee \& Ryu, 2003).

대표적인 기하학 문양은 다음과 같다(一見 輝 \& 八木 和子, 1999; Lee \& Ryu, 2003).

- 그래픽 문양(Graphic patten)

교차, 교차점, 십자 긋기와 같이 직선이나 곡선 등이 교차하 여 얻어진다. 현대적이고 세련되며 개성이 강한 이미지가 특징 이다.

- 옵티컬 문양(Optical pattern)

옵티컬 아트의 영향을 받은 직선과 곡선에 의한 평면분할로 서 착시효과가 있어 평면이 왜곡되어 보이거나 움직이는 느낌 의 리드미컬한 인상을 준다.

- 그래픽 지오메트릭 문양(Graphic geometric pattern)

제도 용구로 반듯하게 그린 기하학 문양이다.

- 캘리그래픽/슈퍼그래픽 문양(Calligraphic/Supergraphic pattern)

대담한 그래픽 형태로 큰 모티브를 사용하여 흐르는 듯한 곡 선에 의한 문양을 흑백 또는 다양한 색상으로 변화를 주어 반
복하여 문양을 형성한다.

- 몬드리안풍 프린트(Mondrian look print)

몬드리안의 그림과 같이 수평선과 수직선, 정사각형, 직사각 형만을 사용해서 형성된 문양이다.

\section{3. 패션 컬렉션에 나타난 기하학 문양의 특징}

본 연구에서는 기하학 문양의 대표적 이미지 선정을 위해 삼 성 디자인넷에서 제공하는 2009년 S/S부터 2014년 S/S까지 세 계 4대 패션 컬렉션 이미지 자료를 활용하였다. 이 때 도트, 스트라이프, 체크와 같은 일정한 패턴을 가지는 기하학 문양은 제외하고 불규칙적이며 유동적인 곡선을 나타내는 기하학 문양 을 중심으로 이미지 자료를 분류하였고, 분류된 이미지들의 대 부분은 이론적 배경에서 제시한 대표적 기하학 문양으로 구별 할 수 있었다.

Fig. 1 44는 2009년 S/S부터 2014년 S/S까지의 New York, Paris, Milan, London의 패션 컬렉션에 나타난 기하학 문양의 대표적 이미지를 년도에 따른 시즌별로 나타낸 것이다.

Fig. 1 4에 나타낸 바와 같이 2009년 S/S 시즌에 있어 기하 학 문양이 많이 보여 지지는 않았으나, 기하학 문양은 블랙과 화이트의 조합이 지속적으로 보여 지며, 선·면을 통한 기하학 적 구성과 마치 만화경을 들여다보는 듯한 화려한 색상과 다양

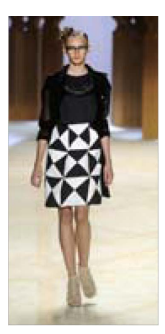

Fig. 1. 3.1 Phillip Lim, $2009 \mathrm{~S} / \mathrm{S}$. www.samsungdesig n.net

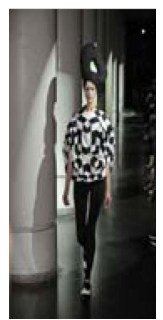

Fig. 9. Junya Watanabe, 2010 $\mathrm{S} / \mathrm{S}$. $w w w$. samsungdesign.net
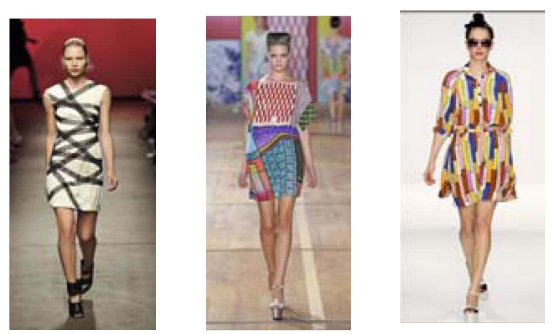

Fig. 3. Basso \& Fig. 4. PPQ,

Fig. 2.

Thakoon, 2009 $\mathrm{S} / \mathrm{S}$. S.www.samsung esign.net

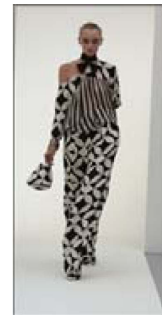

Fig. 10.

Temperley London, 2010 S/S. $w w w$. samsung design.net
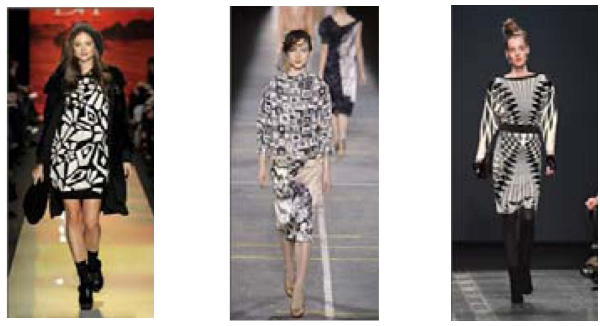

Fig. 5. Diane von Fig. 6. Dries Van Fig. 7. Ice Berg, Furstenber, 2009

Noten,

$2009 \mathrm{~F} / \mathrm{W}$

www. samsung

samsung design.net samsungdesign.net design.net

esign.net

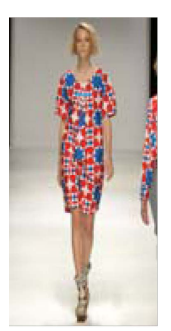

Fig. 11. Eley

Kishinoto, 2010

$\mathrm{S} / \mathrm{S}$. $w w w$.

samsung

design.net

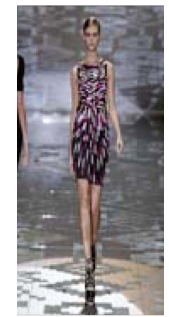

Fig. 12. Gucci,

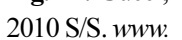

samsungdesign

net

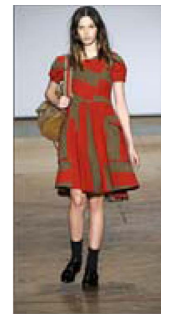

Fig. 13. Marc $b$

Marc Jacobs, 2010

$\mathrm{F} / \mathrm{W}$. $w w w$.

samsungdesign.net sam

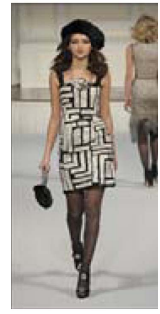

Fig. 14. Oscar

deLa Renta, 2010 F/W. $w w w$.

net

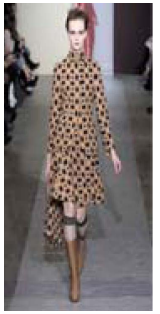

Fig. 15. Marni, 2010 F/W. $w w w$ samsungdesign. net

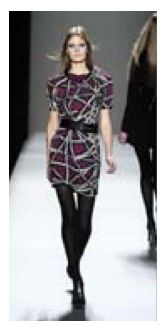

Fig. 8. Nicole Miller, 2009 F/W. www. samsung design.net

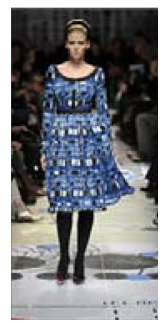

Fig. 16. Prada, 2010 F/W. $w w w . s$ amsungdesign.net 
한 크기의 모티브를 현란하게 조합시켜 불규칙적이며 대비적인 형태로 나타났다. Fig. 5 8에 나타낸 바와 같이 2009년 F/W 시즌에 있어 기하학 문양은 구성주의 느낌을 전달하며 모노컬 러를 사용하여 강하고 절제된 인상을 주고 있으며, 규칙적이기 보다는 불규칙적인 형태가 더 많이 보여 졌다.

Fig. 9 12에 나타낸 바와 같이 2010년 S/S 시즌의 기하학 문양은 2009년 $\mathrm{F} / \mathrm{W}$ 시즌의 모노컬러의 구성주의 느낌과 색상 대비가 선명한 컬러를 사용한 광학적 느낌의 옵티컬 문양, 픽 셀라이즈된 문양으로 모노톤의 블랙 컬러와 퍼플과 같은 액센 트 컬러의 조합과 패턴의 길이방향을 이용해 역동적 이미지를 보여주었다. Fig. 13 16에 나타낸 바와 같이 2010년 F/W 시 즌 기하학 문양은 60 년대 옵아트의 경향을 새롭게 이어가는 기 하학 프린트물과 패턴의 크기를 달리하여 불규칙적으로 배열하 였고 사용된 컬러는 $\mathrm{S} / \mathrm{S}$ 시즌에 비해 한층 간결하게 나타났다.

Fig. 17 20에 나타낸 바와 같이 2011년 S/S 시즌 기하학 문양은 퍼즐조각과 같은 패턴들을 액센트 컬러로 조합하여 팝 아트적인 이미지와 블랙, 화이트의 모던한 콤비네이션 외에 톤 다운된 오렌지 컬러는 1970년대의 레트로 분위기를 나타내었 다. Fig. 21 24에 나타낸 바와 같이 2011 F/W 시즌 기하학 문양은 미래적 또는 디지털 분위기를 느낄 수 있도록 벽에 부 딪혀 깨지거나 다른 각도로 퍼져나가는 듯한 이미지에 다이아
몬드, 사각, 지그재그 등 다양한 모티브를 혼합하고 오렌지, 그 린, 퍼플과 같은 액센트 컬러와 블랙 컬러로 에스닉한 분위기 로 나타났다.

Fig. 25 28에 나타낸 바와 같이 2012년 S/S 시즌 기하학 문양은 화이트 바탕에 블루, 블랙, 레드 등 하나의 컬러로 반 복해서 이어지는 3 차원적 옵아트 문양과 2011년도의 모던한 변 화가 지속적으로 나타나 심플한 기하학적 변형과 강렬한 색체 사용이 특징이다. Fig. 29 32에 나타낸 바와 같이 2012년 F/ $\mathrm{W}$ 시즌 기하학 문양은 $\mathrm{S} / \mathrm{S}$ 시즌과 달리 비비드한 컬러와 선명 한 다크 톤, 블랙의 컨트라스트로 강렬한 인상을 주는 컬러들 을 사용하여 벽지나 인테리어용 패브릭을 연상시키는 규칙적인 월페이퍼 문양이 트랜드로 부각되었다.

Fig. 33 36에 나타낸 바와 같이 2013년 S/S 시즌 기하학 문양은 60 년대의 레트로 무드가 대세를 이루며 시즌 키 패턴 들을 복합적으로 믹스하여 나타내어 서로 다른 패턴들을 패치 워크와 콜라주의 형태로 혼합하여 기하학 문양이 복합적으로 나타났다. Fig. 37 40에 나타낸 바와 같이 2013년 F/W 시즌 기하학 문양은 크랙된 느낌이나 정교한 좌우 대칭 패턴으로 깔 끔한 그래픽 그리드가 추상적으로 보였으며, 밀리터리나 캐주 얼을 대표하는 카무플라주 모티브가 정통적인 컬러 조합이 아 닌 블랙과 화이트, 그레이 조합에 블루, 핑크 등 액센트 컬러

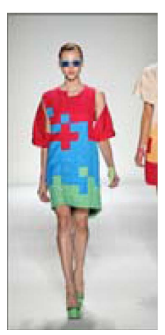

Fig. 17.

Alexandre

Herchovitch, 2011

$\mathrm{S} / \mathrm{S}$. $w w w$.

samsungdesign.

net

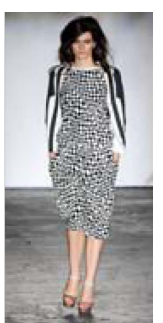

Fig. 25. Clements Fig. 26. Loewe, Fig. 27. Riberiro, 2012 S/S. 2012 S/S. Stella www.samsungdesi www.samsungd McCartney, gn.net

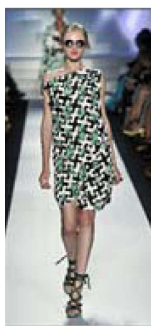

Fig. 18. Diane von Fursten berg, $2011 \mathrm{~S} / \mathrm{S}$. S/S. www.samsungd www.samsungde esign.net sign.net
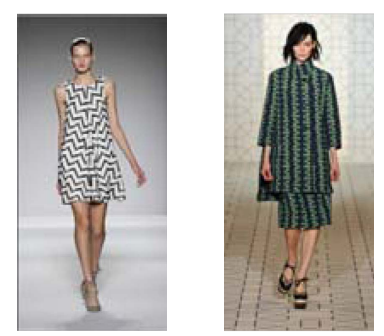

Fig. 21. Marni,

Fig. 20. Sportmax, $2011 \mathrm{~S} / \mathrm{S}$.

$2011 \mathrm{~F} / \mathrm{W}$.

www.samsungdesi www.samsungd gn.net esign.net
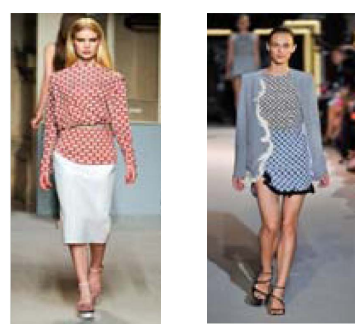
$2012 \mathrm{~S} / \mathrm{S}$. www.samsungde www.sam
sign.net

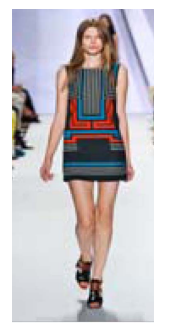

Fig. 28.

Lacoste, 2012

$\mathrm{S} / \mathrm{S}$. $w w w$. samsung design.net

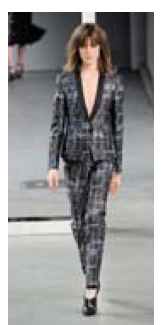

Fig. 29. Derek Lam, 2012 F/W. www.samsungdesi gn.net

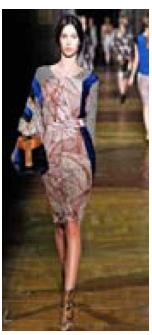

Fig. 22. Dries VanNoten, 2011 F/W.

www.samsungdesi gn.net

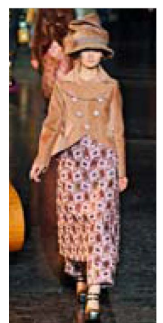

Fig. 30. Louis Vuitton, 2012 F/W.

www.samsung design.net
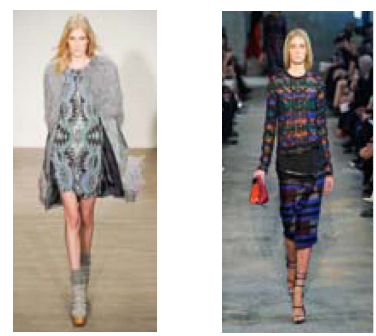

Fig. 23. Matthew Fig. 24. Proenza Williamson, 2011 Schouler, 2011 F/W. $\quad \mathrm{F} / \mathrm{W}$.

gn.net ign.net

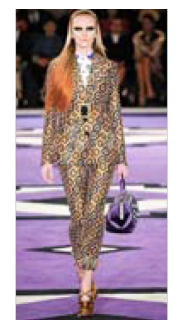

Fig. 31. Prada, 2012 F/W. ungdesi 2012 F/W. gn.net www.samsungdes ign.net

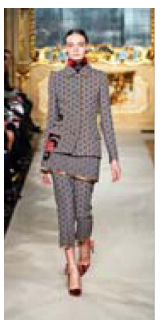

Fig. 32. Aquilano E Rimondi, 


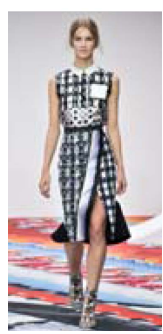

Fig. 33. Peter Pilotto, 2013 www.samsungdesi Schouler, 2013 gn.net

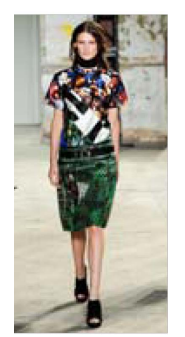

Fig. 34.

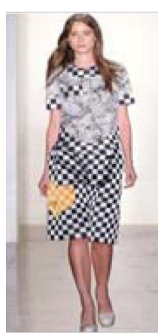

Fig. 35 . Alexandre Herchcovitch, $2013 \mathrm{~S} / \mathrm{S}$.

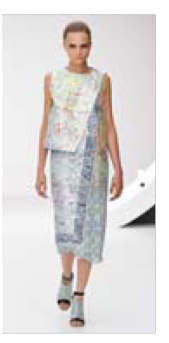

Fig. 36. Mary Katrantzou, $2013 \mathrm{~S} / \mathrm{S}$. www.samsungd gn.net www.samsungd www.samsungde esign.net esign.net sign.net

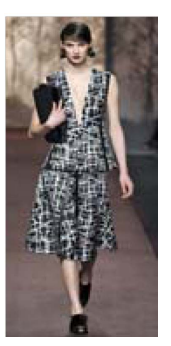

Fig. 37. Marni,

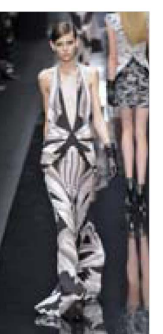

Fig. 38. Leonard, Fig. 39. Michael Fig. 40. 2013 F/W.

www.samsungdesi gn.net

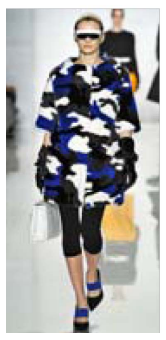

Kors, 2013 F/W. Christophrt

www.samsungdesi Kane, 2013 F/W. gn.net

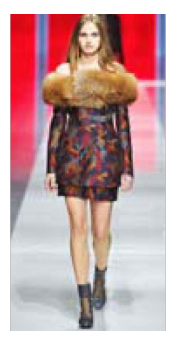

www.samsungdes ign.net

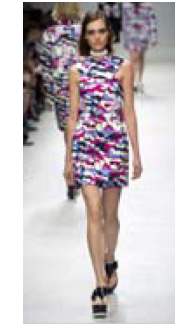

Fig. 41. Carven, 2014 S/S. www.samsungdes ign.net

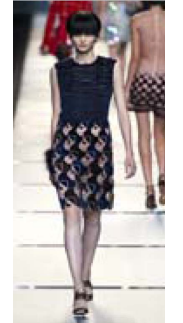

Fig. 42. Fend 2014 S/S.

www.samsungd esign.net

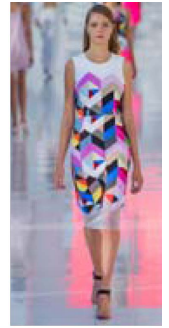

Fig. 43. Preen 2014 S/S.

www.samsungd esign.net

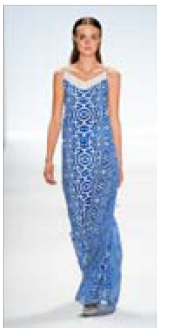

Fig. 44. Richard Chai, $2014 \mathrm{~S} / \mathrm{S}$. www.samsungd esign.net

를 조합하여 화려하게 나타났다.

Fig. 41 44에 나타낸 바와 같이 2014년 S/S 시즌 기하학 문양은 지난 2013년 F/W 시즌에 보여진 컬러풀한 카무플라주 문양과 중간 사이즈의 기하학적 모티브를 과감하게 활용, 60 년 대의 레트로 분위기를 연출하고 투톤 또는 멀티 컬러의 사용으 로 화려하게 나타냈다.

이상의 이미지 자료들을 관찰 - 분석한 결과, 기하학 문양은 모티브의 크기 변화, 다양한 패턴들의 믹스매치, 불규칙한 형태 가 각 시즌의 트랜드 컬러와 다양하게 표현됨을 알 수 있었다.

\section{4. 디자인 개발}

\section{1. 디자인 개발 배경}

소비자들은 개개인의 성향과 함께 사회적인 현상, 환경, 분 위기에 영향을 받아 과거보다 더 많은 욕구에 대한 표현과 반 응이 소비로 연결되고 있다.

2009년 S/S 시즌부터 2014년 S/S 시즌까지 New York, Paris, Milan, London의 세계 4대 패션 컬렉션에서 사용된 직 물의 문양 유형을 분석한 결과, 유동적으로 변화하는 사회에 맞 추어 항상 새롭고 개성적인 것을 추구하는 현대의 소비자 감성 은 레트로, 친환경, 신소재 등과 접목되고 있으며, 기하학 문양 은 모티브의 크기 변화, 다양한 패턴들의 믹스매치, 불규칙한

형태를 활용하여 다양하게 표현될 것으로 예상된다.

이에 본 연구에서는 기하학 문양의 분석결과를 바탕으로 일 반직기에 적용 가능한 단순한 모티브를 연결하여 새로운 모티 브가 생성되는 문양, 레트로한 감성의 월페이퍼와 같은 기하학 문양을 중심으로 직물조직 종광디자인을 설계해 보고자 한다.

\section{2. 디자인 컨셉 및 컬러}

효과적인 직물조직 종광설계를 위하여 Greenness, Neo classic, Romantic chic의 3가지 디자인 컨셉 및 컬러를 선정하 였다. 이는 삼성디자인넷의 Pre Trend 자료를 참고하고 최근 트랜드 경향을 분석하여 나타낸 것이다. 따라서 컨셉의 키워드 는 최근 트랜드의 대세를 이루고 있는 친환경, 과거의 것들을 현대적으로 재해석하는 레트로적인 감성표현과 소녀적인 감성 이 현대의 쉬크한 감성과 어울려 표현되도록 설정하였다. 각 컨 셉의 키워드는 다음과 같은 의미를 담고 있다.

\subsubsection{Greenness}

Greenness는 친환경에 관한 트랜드 경향이 두드러지면서 Green의 이미지는 환경과 관련된다. 또한 최근 많은 영화 속에 초록색의 피부를 가진 주인공들이 등장하면서 초록색은 인간들 에게 낮설음, 이색적이라는 의미를 전달하고 있다. 이색적인 것 은 신비로운 분위기를 나타내며, 신비로운 측면에서 바라본 자 연은 기이하고 생명력 있는 상상의 세계를 표현하는데 활용되 어 감성적 코드를 자극할 수 있는 형태로 변형된다. 거칠고 비 현실적인 형태와 빛을 통해 신비롭게 변형된 자연적 요소는 매 력적인 깊고 어두운 컬러들로 구성되어 또 다른 디자인의 영감 을 제시한다.

\subsubsection{Neo classic}

Neo classic은 유행을 타지 않는 클래식한 스타일을 기준으로 과거와 현재, 미래가 공존할 수 있도록 빠르게 변해가는 현대사 회에서 현대적인 새로운 감각을 가지고, 과거를 잃어버리지 않 은 클래식함을 재해석하였다. 현대적인 감성의 새로움을 추구하 면서 고전적이고, 관습적인 클래식한 요소를 과감히 혼합하였 
다. 고전적인 요소와 다양한 문화, 민속적인 요소의 표현은 가 공되지 않은 오래되고 낡은 듯한 소재와 색상, 다양한 벽지 문 양들을 디자인의 형태로 표현하였다. 편안한 감성은 고전적이면 서도 모던하기도 한 스타일을 재창조해내기 위해 지역적 전통으 로부터 전원풍, 평범함, 소박함, 수수함 등의 민속적 이미지가 낭 만적인 이미지와 결합되어 수공예적 측면에서 재현되었다.

\subsubsection{Romantic chic}

Romantic chic는 소녀적인 로맨틱한 분위기에 현대적이면서 도 도도한 섹시미와 30,40 년대의 영향으로 레트로한 분위기를 대표하는 쉬크한 스타일을 나타낸다. 실크처럼 가볍고 경쾌한 소재, 섬세한 디테일 및 소프트 실루엣, 야성적인 모티브의 도 입, 호랑이나 표범, 뱀의 애니멀 프린트의 인조 모피 등을 사 용해서 원시적인 이미지를 페미닌하게 표현하였다.

\subsection{4. 컬러}

설정한 3종류의 컨셉에 따른 컬러는 한층 부드러운 페일톤 과 라이트 그레이쉬 톤의 컬러들을 사용하여 밝고 차분한 분위 기를 형성하였다. 그레이쉬한 컬러들은 순수한 색감보다는 경 계가 모호한 컬러들로 최근 트렌드에서 두드러지는 색상이다.

따라서 $\mathrm{S} / \mathrm{S}$ 시즌은 그린, 옐로우, 레드, 블루 등을 사용하여 전반적으로 밝고 산뜻하면서도 부드럽게 나타낼 수 있는 파스 텔톤의 컬러를 사용하며, $\mathrm{F} / \mathrm{W}$ 시즌은 따뜻하며 부드러운 컬러 인 브라운 계열과 레드 계열을 주로 사용하되, 짙은 채도와 명 도는 피하여 중압감은 없으면서 부드러운 중도의 느낌을 줄 수 있는 컬러를 사용하고자 한다.

\section{3. 직물조직 종광설계}

패션 컬렉션에 나타난 직물의 기하학 문양을 분석한 결과와 Greenness, Neo classic, Romantic chic의 3가지 디자인 컨셉 을 바탕으로 하여 직물조직의 종광디자인을 설계할 수 있는 직 조 $\mathrm{CAD}$ 프로그램(Tex Pro, (주)영우)을 활용, 총 4종의 기하 학 문양의 직물조직 종광디자인을 설계하였다. 표 2는 디자인 컨셉에 따른 종광 설계도를 나타낸 것이다.

Greenness를 컨셉으로 설계한 종광디자인은 현대사회의 도심 속 건물을 모티브로 다양한 크기의 사각형들을 믹스하여 기하 학적 형태를 재탄생시켜 표현하였다. 많은 종광을 사용하여 표 현되므로 자카드와 같은 이미지가 나타나도록 설계하였다. 종 광 설계 시, 1 repeat의 경사는 40 올, 위사는 60 올이며, 40 종광 으로 설계하였다.

Neo classic을 컨셉으로 설계한 종광디자인은 자카드 패턴에 서만 볼 수 있었던 섬세함과 포클로릭(folkloric) 감성을 표현하 였다. 종광 설계 시, 1 repeat의 경사는 40 올, 위사는 60 올이며, 20 종광으로 설계하였다.

Romantic chic를 컨셉으로 설계한 첫 번째 종광디자인은 최 근 레트로의 영향을 받아 작은 크기의 기하학적인 패턴을 이용 하였으며, 기하학적인 사각형 형태의 모서리들이 조합되어 새
Table 1. Weaving draft by design concepts

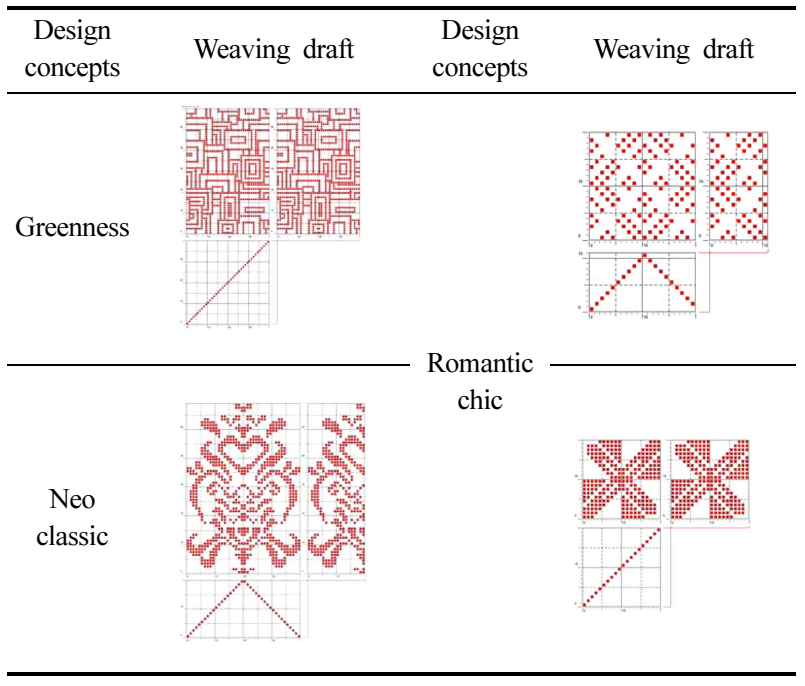

로운 형태가 나타나도록 표현하였다. 종광설계 시, 1repeat의 경 사와 위사는 각각 20 올이며, 11 종광으로 설계하였다. 두 번째 종광디자인은 선과 면의 결합으로 만들어진 심플하면서도 레트 로한 모티브를 반복적으로 배열하여 기하학적으로 표현하였다. 종광설계 시, 1 repeat의 경사와 위사는 각각 20 올이며, 20 종광 으로 설계하였다.

\section{4. 실 설계}

Table 1에 나타낸 바와 같이 Greenness, Neo classic, Romantic chic의 3가지 컨셉으로 종광디자인을 설계한 후, (주) 영우의 직조 $\mathrm{CAD}$ 프로그램인 $\mathrm{Tex}$ Pro를 이용하여 제직을 위한 실을 설계하였다. S/S 시즌에 사용할 실은 주로 견사, 면사, 리 넨사를 사용하여 얇은 직물들을 설계하고자 하였다. 견사는 20 데니어의 강연사로 설계하였으며, 면사는 $100 ~ 120$ 수의 코머사, 리넨사는 80 120수의 가는 실로 꼬임수를 달리하며 까슬거리 면서도 부드러운 특성을 나타내도록 설계하였다. 또 $\mathrm{F} / \mathrm{W}$ 시즌 에 사용할 실은 주로 방모사와 소모사를 사용하였으며, 방모사 는 $\mathrm{S}$ 고임으로 15 수에서 60 수까지 다양한 굵기의 실을 사용하 여 설계하였고, 소모사는 얇고 고급스럽게 표현하고자 150 수를 사용하여 S고임과 Z고임으로 설계하였다.

Table 2는 디자인 컨셉에 따른 $\mathrm{S} / \mathrm{S}$ 시즌용 직물에 사용될 실의 특성을 나타낸 것이며, Table 3 은 디자인 컨셉에 따른 F/ $\mathrm{W}$ 시즌용 직물에 사용될 실의 특성을 나타낸 것이다.

\section{5. 직물 설계}

직물의 설계는 같은 실을 사용하더라도 실의 색상에 따라 다 양한 감성으로 표현될 수 있으나 경·위사의 색상을 달리하여 샘플직물을 생산하는 데는 많은 시간이 소요되므로 단시간에 많은 요소를 변화시켜 다양한 직물을 시뮬레이션할 수 있는 직 조 $\mathrm{CAD}$ 프로그램인 Tex $\operatorname{Pro}(($ 주)영우)를 사용하였다. 
Table 2. Characteristics of the yarns used for $\mathrm{S} / \mathrm{S}$ fabrics by design concepts

\begin{tabular}{|c|c|c|c|c|c|c|c|}
\hline \multirow{2}{*}{$\begin{array}{l}\text { Design } \\
\text { concept }\end{array}$} & \multirow{2}{*}{ Weaving draft } & \multirow{2}{*}{\multicolumn{2}{|c|}{ Fabric type }} & \multicolumn{4}{|c|}{ Characteristics of the yarns } \\
\hline & & & & Yarn type & Direction of twist & Twist number & Thickness \\
\hline \multirow{4}{*}{ Greenness } & 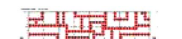 & \multirow{2}{*}{1} & warp & Silk & $\mathrm{S}$ & 75 & 20D \\
\hline & 司高 & & weft & Silk & S & 75 & $20 \mathrm{D}$ \\
\hline & & \multirow{2}{*}{2} & warp & Silk & $\mathrm{S}$ & 75 & $20 \mathrm{D}$ \\
\hline & 舁 & & weft & Silk & $\mathrm{S}$ & 75 & 20D \\
\hline \multirow[b]{2}{*}{$\begin{array}{l}\text { Neo } \\
\text { classic }\end{array}$} & & \multirow[b]{2}{*}{3} & warp & Cotton & $\mathrm{S}$ & 75 & $100 ' \mathrm{~S}$ \\
\hline & & & weft & Cotton & $\mathrm{S}$ & 75 & 100 'S \\
\hline \multirow{8}{*}{$\begin{array}{c}\text { Romantic } \\
\text { chic }\end{array}$} & & \multirow{2}{*}{4} & warp & Linen & $\mathrm{S}$ & 20 & 80 'S \\
\hline & & & weft & Linen & $\mathrm{S}$ & 20 & 80 'S \\
\hline & & \multirow{2}{*}{5} & warp & Cotton & Z & 75 & 120 'S \\
\hline & & & weft & Cotton & S & 75 & 120 'S \\
\hline & \multirow{4}{*}{ 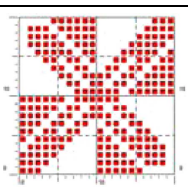 } & \multirow{4}{*}{6} & \multirow{2}{*}{ warp } & Linen & $\mathrm{S}$ & 75 & $120^{\prime} \mathrm{S}$ \\
\hline & & & & Silk & $\mathrm{S}$ & 75 & $20 \mathrm{D}$ \\
\hline & & & \multirow{2}{*}{ weft } & Linen & S & 75 & $120 ' \mathrm{~S}$ \\
\hline & & & & Silk & S & 75 & $20 \mathrm{D}$ \\
\hline
\end{tabular}

Table 3. Characteristics of the yarns used for F/W fabrics by design concepts

\begin{tabular}{|c|c|c|c|c|c|c|c|}
\hline \multirow{2}{*}{ Design concept } & \multirow{2}{*}{ Weaving draft } & \multirow{2}{*}{\multicolumn{2}{|c|}{ Fabric type }} & \multicolumn{4}{|c|}{ Characteristics of the yarns } \\
\hline & & & & Yarn type & Direction of twist & Twist number & Thickness \\
\hline \multirow[b]{2}{*}{ Green ness } & & & warp & woolen & $\mathrm{S}$ & 5 & $40 ' \mathrm{~S}$ \\
\hline & 期面品 & 7 & weft & woolen & $\mathrm{S}$ & 30 & 30 'S \\
\hline \multirow{4}{*}{ Neo classic } & & \multirow{2}{*}{8} & warp & worsted & $\mathrm{S}$ & 75 & 150 'S \\
\hline & & & weft & worsted & $\mathrm{S}$ & 75 & 150 'S \\
\hline & & \multirow{2}{*}{9} & warp & woolen & $\mathrm{S}$ & 5 & $60 ' S$ \\
\hline & & & weft & woolen & $\mathrm{S}$ & 5 & 60 'S \\
\hline \multirow{8}{*}{ Romantic chic } & & \multirow{2}{*}{10} & warp & worsted & Z & 30 & 150 'S \\
\hline & & & weft & worsted & Z & 30 & 150 'S \\
\hline & & \multirow{2}{*}{11} & warp & woolen & $\mathrm{S}$ & 15 & $15 ' S$ \\
\hline & & & weft & woolen & S & 15 & $15 ' \mathrm{~S}$ \\
\hline & & & warp & woolen & $\mathrm{S}$ & 30 & 30 'S \\
\hline & & & weft & woolen & $\mathrm{S}$ & 30 & 30 'S \\
\hline & & & warp & woolen & $\mathrm{S}$ & 30 & 30'S \\
\hline & & 13 & weft & woolen & $\mathrm{S}$ & 30 & 30'S \\
\hline
\end{tabular}

Table 4는 디자인 컨셉에 따라 설계된 종광디자인에 Table 1 에 나타낸 $\mathrm{S} / \mathrm{S}$ 시즌용으로 설계된 실을 사용하여 시뮬레이션 한 직물 이미지를 나타낸 것이다
직물 1과 2는 Greenness를 디자인 컨셉으로 설계한 이미지 로 직물 1 은 경사에 pink grayish를, 위사에 green gray를 주 색상으로 사용하였고 직물 2 는 경사에 light blue를, 위사는 
Table 4. S/S Season fabric simulation images by design concepts

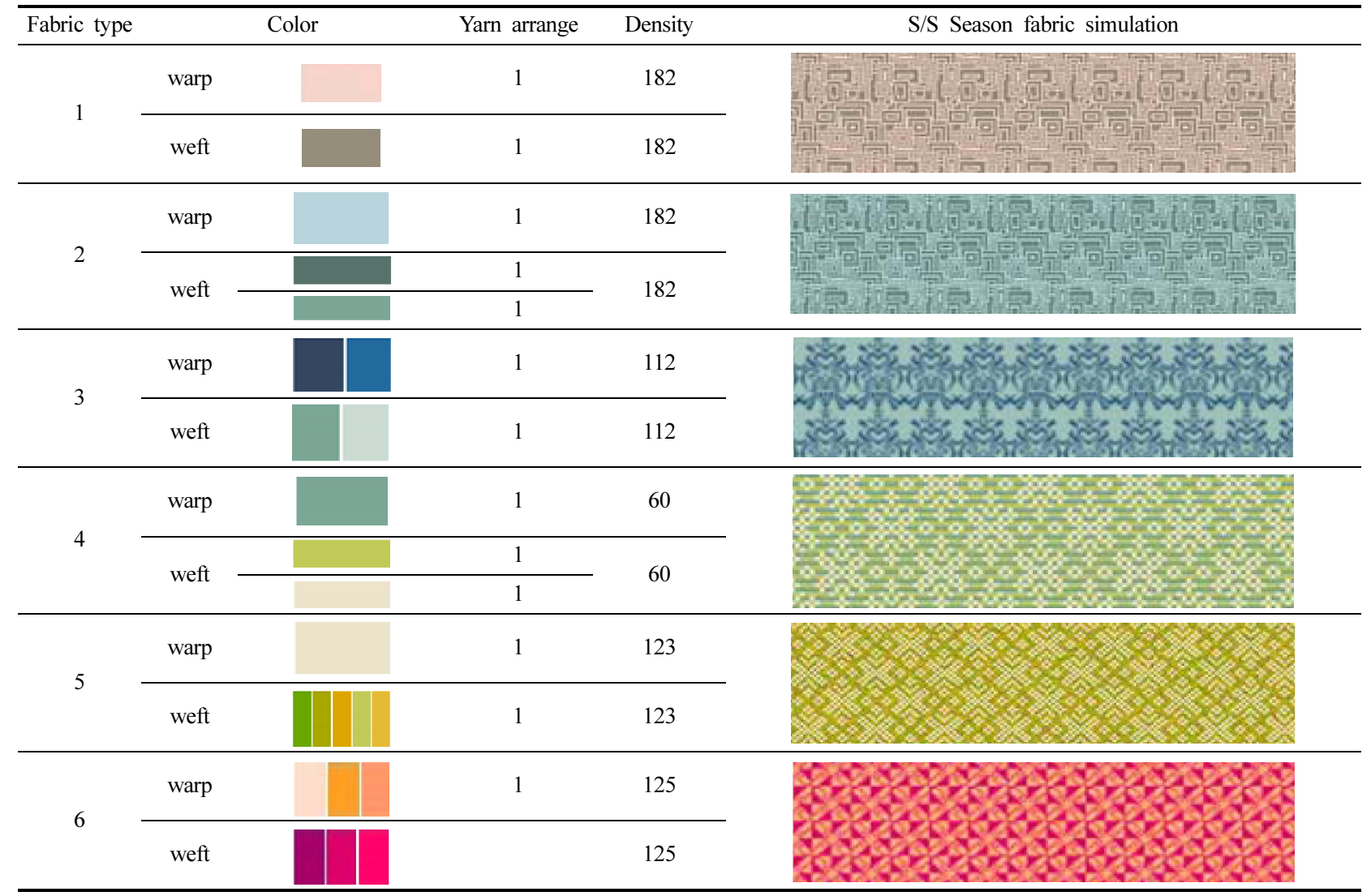

green계열을 주색상으로 사용하여 차분하고 고요하게 표현하였 다. 조직점을 강조하기 위해 경사에 단색, 위사에 동색계열로 각각 실을 배열하였다.

직물 $3 \mathrm{Neo}$ classic을 디자인 컨셉으로 설계한 이미지로 경 사에 dark blue계열을 주색상으로 사용하고, 위사는 light blue 와 green pale을 주색상으로 사용하여 섬세한 포클로릭 감성이 강조되도록 하였다. 설계된 직물은 민속문양이 주로 사용되는 인테리어 소재 외에 캐주얼 의류용으로도 확대 적용이 가능할 것으로 판단된다. 직물 4 6은 Romantic chic를 디자인 컨셉으 로 설계한 이미지들이다.

직물 4는 경사를 beige 색상으로, 위사를 green과 light green을 사용하여 산뜻한 이미지로 표현하였으며, 또한 단색의 경사를 사용하여 조직감이 두드러지게 표현하였다. 직물 5 는 경사에 light beige를 주색상으로 사용하고, 위사에 green계열을 주색상으로 사용하여 포근한 느낌으로 표현하였으며, 설계된 직 물은 주로 인테리어 또는 자켓용으로 사용하고자 한다.

직물 6은 경사를 orange계열, 위사를 puple, pink계열을 주 색상으로 사용하여 경쾌하면서 상큼한 이미지를 표현하고 고급 스러운 소재의 사용으로, 여성용 블라우스에 사용하고자 한다.

표 5는 디자인 컨셉에 따라 설계된 종광디자인에 표 3에 나 타낸 $\mathrm{F} / \mathrm{W}$ 시즌용으로 설계된 실을 사용하여 시뮬레이션 한 직 물 이미지를 나타낸 것이다.
특히 $\mathrm{F} / \mathrm{W}$ 시즌용 직물 중 방모사를 사용한 경우는 기모가 공의 여부, 기모가공의 정도에 따라 다양하게 설계하였으며, 일 반적으로 기모가공을 통해 부드러운 촉감과 보온성의 향상을 기대할 수 있다.

직물 7은 Greenness를 디자인 컨셉으로 설계한 직물 이미지 로 경사에 brown pale톤을 주색상으로 사용하고, 위사는 dark brown계열을 주색상으로 사용하여, 현대사회의 도시환경을 모 티브로 하여 차가운 도시에서도 따뜻한 감성을 느낄 수 있도록 표현하였다. 설계된 직물은 주로 여성용 스커트나 코트 소재로 사용하고자 한다. 또한 직물에 기모가공을 하여 기모정도에 따 라 나타낸 표면감으로 따뜻한 촉감 및 보온성 증대를 기대할 수 있다.

직물 8 9는 Neo classic을 디자인 컨셉으로 설계한 이미지로 경사는 dark green계열을 주색상으로 하고, 위사는 dark red계 열을 주색상으로 하여 중채도와 저채도의 배색으로 점잖고, 안 정된 느낌이 나도록 표현하였다. 직물 8 은 소모사를 사용하여 깔끔한 표면감을 나타내도록 설계한 반면, 직물 9는 방모사를 사용하여 제직한 이미지로 두껍고 따뜻한 느낌의 직물로 설계 하였으며, 표면에 기모가공을 하여 보온성 증대를 기대할 수 있 으며 기모가공의 정도에 다라 문양의 선명함도 달라지게 설계 하였다. 설계된 직물은 주로 겨울철 두꺼운 원피스 또는 코트 용과 앤틱한 인테리어 소재로도 사용할 수 있다. 
Table 5. F/W Season fabric simulation images by design concepts

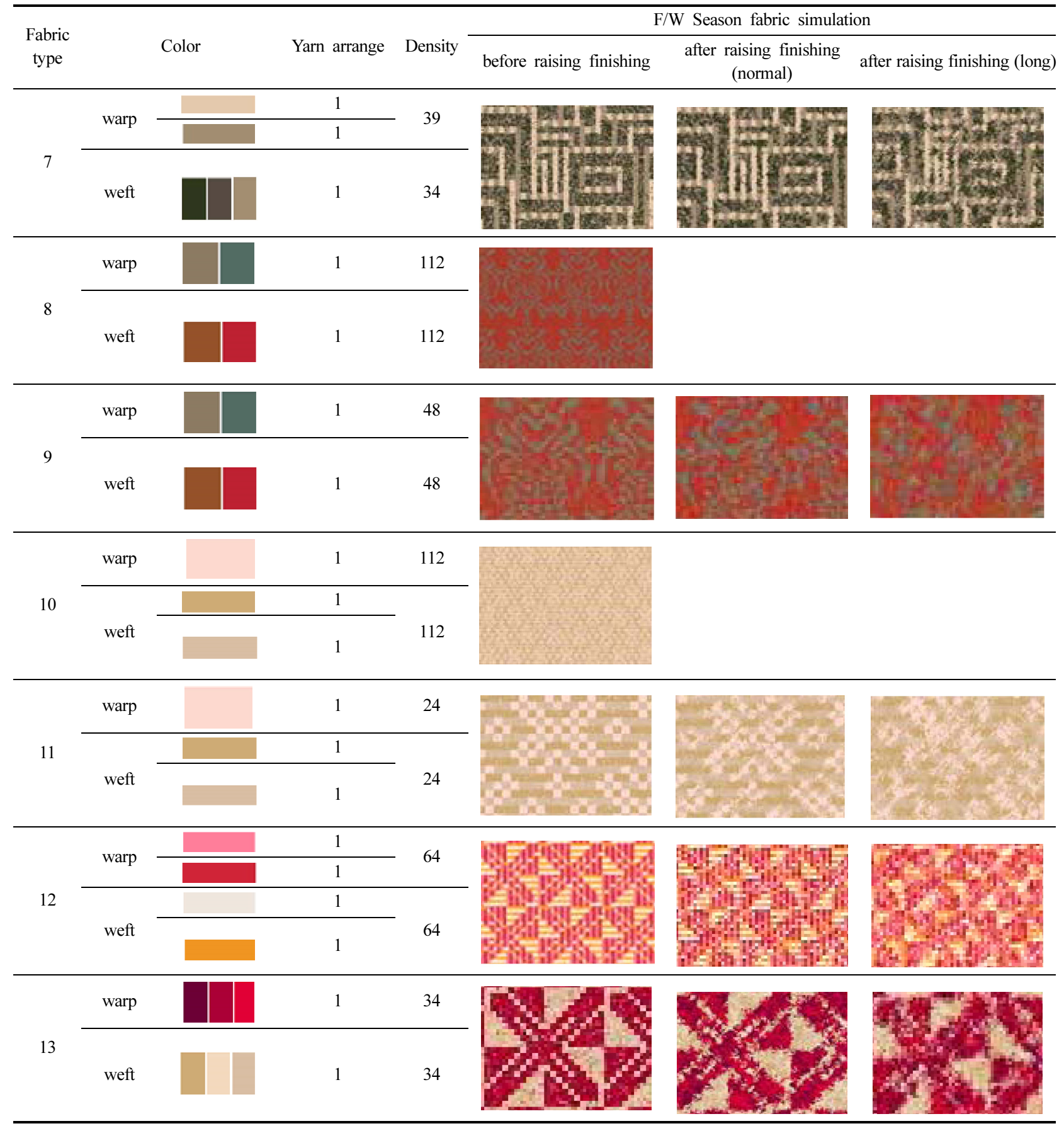

직물 10 13은 Romantic chic를 디자인 컨셉으로 하여 설계 한 직물 이미지로 직물 10 과 11 은 경사에 light pink를, 위사 는 beige계열을 사용하였으며, 특히 직물 10 은 우아하고 여성 스러운 이미지에 부드러운 느낌을 표현하기 위해 소모사를 사 용하여 제직하였다. 직물 11 은 약연의 거친 방모사를 사용하여 코트용 소재로 제직하였으며 기모가공 시, 기모 정도에 따라 외 관 변화를 나타내었으며 러스틱한 촉감 및 보온성 증대를 느낄 수 있을 것으로 기대된다.
직물 12 는 경사에 $\mathrm{S} / \mathrm{S}$ 시즌과 유사한 계열의 bright red계열 을 사용하고, 위사에는 밝은 beige와 orange를 1올씩 교대로 배열하여 밝고 따뜻한 느낌을 표현하였으며, 방모사를 사용하 여 두껍고, 러스틱한 직물로 설계하였다.

직물 13 은 경사로 red계열을, 위사로 light brown계열을 사용 하여 짙은 경사의 조직점이 두드러지게 표현하였다. 설계된 직 물은 직물 12 에 비하여 밀도를 낮추어 제직하고 기모가공을 한 표면감은 편성물과 유사하여 캐주얼 의류에 사용하고자 한다. 


\section{5. 결 론}

본 연구는 최근 5년간 세계 4대 컬렉션(New York, Paris, Milan, London)에 나타난 직물의 문양 중 가장 빈도수가 높은 기하학 문양을 날염이 아닌 직조에 의한 문양으로 표현하기 위 해 직조 $\mathrm{CAD}$ 프로그램을 활용하였다. 직조에 의한 기하학 문 양은 특수직기가 아닌 일반직기에 적용할 수 있는 종광디자인 으로 설계함으로써 빠르게 변화하는 패션 트렌드에 따른 다품 종 소량생산에 의한 고부가가치 패션소재 개발 및 생산에 기초 자료로 활용되어 섬유산업 발전에 도움이 되고자 한다. 이상의 과정을 통해 다음과 같은 결론을 얻었다.

1. 패션 컬렉션에 나타난 기하학 문양의 특징을 분석한 결과, 기하학 문양은 모티브의 크기 변화, 다양한 패턴들의 믹스매치, 불규칙한 형태가 각 시즌의 트렌드 컬러와 다양하게 표현됨을 알 수 있었다.

2. 패션 컬렉션에 나타난 기하학 문양을 분석한 결과를 바탕 으로 효과적인 직물조직 패턴설계를 위하여 Greenness, Neo classic, Romantic chic의 3가지 디자인 컨셉을 설정하였고, 기 하학 문양을 일반직기에 적용 가능한 종광디자인으로 설계할 수 있다.

3. 직조 $\mathrm{CAD}$ 프로그램을 활용하여 종광설계, 실설계 단계를 거쳐 직물설계에 적용하여 시률레이션 이미지를 확인함으로써 직접 예비샘플을 제작하는 것보다 생산성을 향상시킬 수 있을 것으로 기대된다.

4. 동일한 종광디자인으로 원사의 종류, 꼬임수, 꼬임방향, 굵 기, 경위사의 밀도변화, 가공여부 및 색상에 따라 $\mathrm{S} / \mathrm{S}, \mathrm{F} / \mathrm{W}$ 시 즌에 적합한 다품종 소량생산의 고부가가치 디자인 직물을 생 산할 수 있다.

\section{References}

Alexandre Herchovitch 2011 S/S. (n.d.). www.samsungdesign.net. Retrieved August 23, 2010, from http://www.samsungdesign.net/ Collection/ForWomen/new_source.asp? sourcename= 38_239_5687_12.jpg\&itemidx $=239 \&$ designeridx $=5687 \&$ seq $=12$ $\&$ an $=38 \&$ sourcewidth $=1198 \&$ sourceheight $=1800 \&$ initImg $=12$

Alexandre Herchovitch 2013 S/S. (n.d.). www.samsungdesign.net. Retrieved November 17, 2013, from http://www.samsungdesign. net/Collection/ForWomen/New_collection.asp?an=53\&itemidx $=$ $324 \&$ item $=$ Overview\&sec_select=Pattern\&year $1=2013 \&$ season= ss

Aquilano E Rimondi 2012 F/W. (n.d.). www.samsungdesign.net. Retrieved November 17, 2013, from http://www.samsungdesign. net/Collection/ForWomen/new_source.asp?sourcename $=$ 49_299_8602_1.jpg\&itemidx $=299 \&$ designeridx $=8602 \&$ seq $=1 \&$ a $\mathrm{n}=49$ \&sourcewidth $=690$ \&sourceheight $=1057$ \&initImg $=1$

Basso \& Brooke 2009 S/S. (n.d.). www.samsungdesign.net. Retrieved July 28, 2010, from http://www.samsungdesign.net/Collection/ ForWomen/new_source.asp? sourcename $=28 \_168 \_2982$ 21.jpg\&itemid $x=168 \&$ designerid $x=2982 \&$ seq $=21 \&$ an $=28 \&$ sourc ewidth $=599 \&$ sourceheight $=900 \&$ initImg $=21$

Carven 2014 S/S. (n.d.). www.samsungdesign.net. Retrieved Junuary 4 , 2014, from http://www.samsungdesign.net/Collection/ForWomen/ new_source.asp? sourcename $=63 \_380 \_11862 \_4 . j p g \&$ itemidx $=380$ $\&$ designeridx $=11862 \&$ seq $=4 \&$ an $=63 \&$ sourcewidth $=1280 \&$ source height $=1920$ \&initImg $=4$

Choi, K. M., \& Kim, J. J. (2009). A study on the design and appearance characteristics of dobby and fancy yarn fabrics using a textile CAD system. Journal of Korean Traditional Costume, 12(3), 23-36.

Chio, Z. Y. (2010). A study on expression of fabric material using computer weaving: focus on texture expression of plants. Unpublished master's thesis, Duksung Women's University, Seoul.

Christophrt Kane 2013 F/W. (n.d.). www.samsungdesign.net. Retrieved December 22, 2013, from http://www.samsungdesign.net/ Collection/ForWomen/new_source.asp?sourcename $=58 \_346$ 10515_15.jpg\&itemidx $=346 \&$ designerid $x=10515 \&$ seq $=15 \&$ an $=5$ $8 \&$ sourcewidth $=1280 \&$ sourceheight $=1920 \&$ initImg $=15$

Clements Riberiro 2012 S/S. (n.d.). www.samsungdesign.net. Retrieved November 17, 2013, from http://www.samsungdesign. net/Collection/ForWomen/new_source.asp?sourcename $=45 \_282$ 7641_1.jpg\&itemidx $=282 \&$ designerid $=7641 \&$ seq $=1 \&$ an $=45 \&$ so urcewidth $=690 \&$ sourceheight $=1058 \&$ initImg $=1$

Derek Lam 2012 F/W. (n.d.). www.samsungdesign.net. Retrieved November 17, 2013, from http://www.samsungdesign.net/ Collection/ForWomen/new_source.asp ? sourcename= 49_293_8335_45.jpg\&itemidx $=293 \&$ designerid $x=8335 \&$ seq $=45$ $\& \mathrm{an}=49 \&$ sourcewidth $=690$ \&sourceheight $=1058$ \&initImg $=45$

Diane von Furstenberg 2009 F/W. (n.d.). www.samsungdesign.net. Retrieved July 28, 2010, from http://www.samsungdesign.net/ Collection/ForWomen/new_source. asp? sourcename= 29_191_3499_31.jpg\&itemidx $=191 \&$ designeridx $=3499 \&$ seq $=31$ \&an $=29$ \&sourcewidth $=433 \&$ sourceheight $=650$ \&initImg $=31$

Diane von Furstenberg 2011 S/S. (n.d.). www.samsungdesign.net. Retrieved August 23, 2010, from http://www.samsungdesign.net/ Collection/ForWomen/new_source.asp? sourcename= 38_239_5729_17.jpg\&itemidx $=239 \&$ designeridx $=5729 \&$ seq $=17$ \&an $=38 \&$ sourcewidth $=1198 \&$ sourceheight $=1800 \&$ initImg $=16$

Dries Von Noten 2009 F/W. (n.d.). www.samsungdesign.net. Retrieved July 28, 2010, from http://www.samsungdesign.net/Collection/ ForWomen/new_source.asp ? sourcename $=29 \_192 \_3792$ 58.jpg\&itemidx $=192 \&$ designerid $x=3792 \&$ seq $=58 \&$ an $=29 \&$ sourc ewidth $=433$ \&sourceheight $=650$ \&initImg $=58$

Dries Von Noten 2011 F/W. (n.d.). www.samsungdesign.net. Retrieved September 23, 2013, from http://www.samsungdesign.net/ Collection $/$ ForWomen/new_source. asp? sourcename $=41$ 259_6861_41.jpg\&itemidx $=259 \&$ designeridx $=6861 \&$ seq $=41 \&$ an $=41 \&$ sourcewidth $=687 \&$ sourceheight $=1058 \&$ initImg $=35$

Eley Kishinoto 2010 S/S. (n.d.). www.samsungdesign.net. Retrieved July 28, 2010, from http://www.samsungdesign.net/Collection/ ForWomen/new_source.asp? sourcename $=31 \_206 \_4174 \_8$.jpg \&itemid $x=206 \&$ designerid $x=4174 \&$ seq $=8 \&$ an $=31$ \&sourcewidth $=$ 900\&sourceheight $=1352 \&$ initImg $=8$

Fendi 2014 S/S. (n.d.). www.samsungdesign.net. Retrieved January 4, 2014, from http://www.samsungdesign.net/Collection/ForWomen/ new_source.asp?sourcename $=63 \_379 \_11787 \_46 . j p g \&$ itemidx $=37$ $9 \&$ designerid $x=11787 \&$ seq $=46 \&$ an $=63 \&$ sourcewidth $=1280 \&$ sou 
rceheight $=1920$ \&initImg $=46$

Gucci 2010 S/S. (n.d.). www.samsungdesign.net. Retrieved July 28, 2010, from http://www.samsungdesign.net/Collection/ForWomen/ new_source.asp?sourcename $=31 \_207 \_4274 \_58 . j p g \&$ itemidx $=207$ $\&$ designerid $x=4274 \&$ seq $=58 \&$ an $=31 \&$ sourcewidth $=900 \&$ sourceh eight $=1352 \&$ initImg $=58$

Han, S. H. (2000). Fabric pattern designs utilizing CAD textile - Focus on vine pattern -. Journal of Korean Society of Design Science, 13(4), 213-223.

IceBerg $2009 \mathrm{~F} / \mathrm{W}$. (n.d.). www.samsungdesign.net. Retrieved July 28, 2010, from http://www.samsungdesign.net/Collection/ForWomen/ new_source.asp?sourcename $=29 \_190 \_3711 \_39 . j p g \&$ itemidx $=190$ $\&$ designeridx $=3711 \&$ seq $=39 \&$ an $=29 \&$ sourcewidth $=433 \&$ sourceh eight $=650$ \&initImg $=39$

Jenny, U. (2008). Textile and fashion. Seoul: Design Research n' Planning, Inc.

Junya Watanabe 2010 S/S. (n.d.). www.samsungdesign.net. Retrieved July 28, 2010, from http://www.samsungdesign.net/Collection/ ForWomen/new_source.asp?sourcename $=31 \_208 \_4468 \_29 . j p g$ \&itemidx $=208 \&$ designerid $=4468 \&$ seq $=29 \&$ an $=31$ \&sourcewidth $=900 \&$ sourceheight $=1352 \&$ initImg $=29$

Kim, G. J. (2008). A study on complementary application of textile $C A D$ and two-dimensional computer graphic programs. Unpublished doctoral dissertation, Kyunghee University, Seoul.

Kim, Y. S., \& Do, Y. S. (1998). A study on the check pattern design using computer weaving program. The Journal of Korea Society of Craft, 1, 35-59.

Lacoste 2012 S/S. (n.d.). www.samsungdesign.net. Retrieved November 17, 2013, from http://www.samsungdesign.net/ Collection/ForWomen/new_source.asp? sourcename $=45 \_280$ 7604_9.jpg\&itemidx $=280 \&$ designeridx $=7604 \&$ seq $=9 \&$ an $=45 \&$ so urcewidth $=690 \&$ sourceheight $=1058 \&$ initImg $=9$

Lee, J. H. (2008). Curtain fabric design by line \& space - Focusing on $S / S$ trends in 2008, 2009. Unpublished master's thesis, Hongik University, Seoul.

Lee, J. H., \& Park, H. S. (2009). Curtain fabric design by the motive of geometric abstraction pattern - Focusing on F/W trends 2009, 2010 -. The Korea Society of Art and Design, 12(1), 1-22.

Lee, J. J., \& Ryu, H. S. (2003). The geometrical patterns used in the fashion materials. Journal of Food and Industry, 5, 83-91.

Leonard 2013 F/W. (n.d.). www.samsungdesign.net. Retrieved December 22, 2013, from http://www.samsungdesign.net/ Collection/ForWomen/new_source.asp? sourcename= 58_352_10697_19.jpg\&itemidx $=352 \&$ designeridx $=10697 \&$ seq $=1$ $9 \&$ an $=58 \&$ sourcewidth $=1280$ \&sourceheight $=1920 \&$ initImg $=19$

Loewe 2012 S/S. (n.d.). www.samsungdesign.net. Retrieved November 17, 2013, from http://www.samsungdesign.net/Collection/For Women/new_source.asp? sourcename $=45 \_287 \_7960 \_93 . j p g$ \&itemid $x=287 \&$ designerid $x=7960 \&$ seq $=93 \& a n=45 \&$ sourcewidth $=690 \&$ sourceheight $=1058 \&$ initImg $=93$

Louis Vuitton 2012 F/W. (n.d.). www.samsungdesign.net. Retrieved November 17, 2013, from http://www.samsungdesign.net/ Collection/ForWomen/new_source.asp ? sourcename= 49_300_8729_91.jpg\&itemidx $=300 \&$ designerid $x=8729 \&$ seq $=91$ $\&$ an $=49 \&$ sourcewidth $=690 \&$ sourceheight $=1058 \&$ initImg $=91$

Nicole Miller 2009 F/W. (n.d.). www.samsungdesign.net. Retrieved July 28, 2010, from http://www.samsungdesign.net/Collection/
ForWomen/new_source.asp? sourcename=29_191_3541_5.jpg \&itemid $x=191 \&$ designerid $x=3541 \&$ seq $=5 \& a n=29 \&$ sourcewidth $=$ $433 \&$ sourceheight $=650$ \&initImg $=5$

Marc by Marc Jacpbs 2010 F/W. (n.d.). www.samsungdesign.net. Retrieved August 4, 2010, from http://www.samsungdesign.net/ Collection/ForWomen/new_source.asp? sourcename $=33$ 213_4755_1.jpg\&itemidx $=213 \&$ designerid $x=4755 \&$ seq $=1 \& a n=3$ $3 \&$ sourcewidth $=1200 \&$ sourceheight $=1802 \&$ initImg $=1$

Marni 2010 F/W. (n.d.). www.samsungdesign.net. Retrieved August 4, 2010, from http://www.samsungdesign.net/Collection/ForWomen/ new_source.asp?sourcename $=33 \_221 \_4967 \_42 . j p g \&$ itemidx $=221$ $\&$ designeridx $=4967 \&$ seq $=42 \&$ an $=33 \&$ sourcewidth $=1200 \&$ source height $=1802$ \&initImg $=42$

Marni 2011 F/W. (n.d.). www.samsungdesign.net. Retrieved September 23, 2013, from http://www.samsungdesign.net/Collection/ ForWomen/new_source.asp? sourcename $=41 \_258 \_6778 \_74 . j p$ \&itemid $=258 \&$ designerid $x=6778 \&$ seq $=74 \& a n=41 \&$ sourcewidth $=687 \&$ sourceheight $=1058$ \&initImg $=58$

Marni 2013 F/W. (n.d.). www.samsungdesign.net. Retrieved December 22, 2013, from http://www.samsungdesign.net/Collection/ ForWomen/new_source.asp?sourcename $=58 \_351 \_10590 \_34 . j p g$ $\&$ itemid $x=351 \&$ designerid $x=10590 \&$ seq $=34 \& a n=58 \&$ sourcewidt $\mathrm{h}=1280$ \&sourceheight $=1920$ \&initImg $=34$

Mary Katrantzou 2013 S/S. (n.d.). www.samsungdesign.net. Retrieved November 17, 2013, from http://www.samsungdesign.net/ Collection/ForWomen/new_source. asp? sourcename= 53_319_9307_25.jpg\&itemidx $=319 \&$ designeridx $=9307 \&$ seq $=25$ \&an $=3 \&$ sourcewidth $=1280$ \&sourceheight $=1920$ \&initImg $=24$

Matthew Williamson 2011 F/W. (n.d.). www.samsungdesign.net. Retrieved September 23, 2013, from http://www.samsungdesign. net/Collection/ForWomen/new_source.asp?sourcename= 41_255_6708_26.jpg\&itemidx $=255 \&$ designeridx $=6708 \&$ seq $=26$ \&an $=41$ \&sourcewidth $=687 \&$ sourceheight $=1058 \&$ initImg $=26$

Michael Kors 2013 F/W. (n.d.). www.samsungdesign.net. Retrieved December 22, 2013, from http://www.samsungdesign.net/ Collection/ForWomen/new_source.asp ? sourcename= $58 \_342 \_10406 \_4 . j p g \&$ itemidx $=342 \&$ designeridx $=10406 \&$ seq $=4$ \&an $=58 \&$ sourcewidth $=1280$ \&sourceheight $=1920$ \&initImg $=4$

Oh, S., \& Kim, J. S. (2008). A study on the research of the textile pattern design applied by the computer CAD - Focusing on the images of dress and its ornament which appeared in the 1960s -. Journal of Korea Design Forum, 20, 293-305.

Oscar de La Renta 2010 F/W. (n.d.). www.samsungdesign.net. Retrieved August 4, 2010, from http://www.samsungdesign.net/ Collection/ForWomen/new_source.asp? sourcename= 33_213_4805_46.jpg\&itemidx $=213 \&$ designeridx $=4805 \&$ seq $=46$ \&an $=33 \&$ sourcewidth $=1200$ \& sourceheight $=1803 \&$ initImg $=46$

Peter Pilotto 2013 S/S. (n.d.). www.samsungdesign.net. Retrieved November 17, 2013, from http://www.samsungdesign.net/Collection/ For Women/new_source. as p ? sourcename $=$ 53_319_9478_1.jpg\&itemidx $=319 \&$ designeridx $=9478 \&$ seq $=1 \&$ an $=$ $53 \&$ sourcewidth $=1280$ \&sourceheight $=1920$ \&initImg $=1$

PPQ 2009 S/S. (n.d.). www.samsungdesign.net. Retrieved July 28, 2010, from http://www.samsungdesign.net/Collection/ForWomen/ new_source.asp? sourcename $=28 \_168 \_3012 \_25 . j p g$ \&itemidx $=168 \&$ designeridx $=3012 \&$ seq $=25 \& a n=28 \&$ sourcewidth $=59$ 9\&sourceheight $=900 \&$ initImg $=25$ 
Prada 2010 F/W. (n.d.). www.samsungdesign.net. Retrieved August 4, 2010, from http://www.samsungdesign.net/Collection/ForWomen/ new_source.asp?sourcename $=33 \_221 \_4983 \_41 . j p g \& i t e m i d x=221$ $\&$ designeridx $=4983 \&$ seq $=41 \&$ an $=33 \&$ sourcewidth $=1200 \&$ source height $=1802$ \&initImg $=41$

Prada 2012 F/W. (n.d.). www.samsungdesign.net. Retrieved November 17, 2013, from http://www.samsungdesign.net/Collection/For Women/new_source.asp? sourcename $=49 \_299 \_8649 \_52 . j p g$ \&itemidx $=299 \&$ designerid $x=8649 \&$ seq $=52 \&$ an $=49 \&$ sourcewidth $=690 \&$ sourceheight $=1058$ \&initImg $=52$

Preen 2014 S/S. (n.d.). www.samsungdesign.net. Retrieved Junuary 4, 2014, from http://www.samsungdesign.net/Collection/ForWomen/ new_source.asp?sourcename $=63$ 377_11751_13.jpg\&itemidx $=37$ $7 \&$ designerid $x=11751 \&$ seq $=13 \&$ an $=63 \&$ sourcewidth $=1280 \&$ sou rceheight=1920\&initImg $=13$

Proenza Schouler 2011 F/W. (n.d.). www.samsungdesign.net. Retrieved September 23, 2013, from http://www.samsungdesign.net/ Collection/ForWomen/new_source.asp?sourcename $=41 \_254 \_6516 \_46 . j p g \&$ itemid $x=254 \&$ designerid $x=6516 \&$ seq $=4$ $6 \&$ an $=41 \&$ sourcewidth $=687 \&$ sourceheight $=1058 \&$ initImg $=46$

Proenza Schouler 2013 S/S. (n.d.). www.samsungdesign.net. Retrieved November 17, 2013, from http://www.samsungdesign.net/ Collection/ForWomen/new_source.asp? sourcename= 53_318_9294_31.jpg\&itemid $=318 \&$ designerid $x=9294 \&$ seq $=31$ $\&$ an $=53 \&$ sourcewidth $=1280 \&$ sourceheight $=1920 \&$ initImg $=31$

Richard Chai 2014 S/S. (n.d.). www.samsungdesign.net. Retrieved January 4, 2014, from http://www.samsungdesign.net/Collection/ ForWomen/new_source.asp ?sourcename $=63$ 375_11607_11.jpg \&itemid $x=375 \&$ designerid $x=11607 \&$ seq $=11 \& a n=63 \&$ sourcewidt $\mathrm{h}=1280 \&$ sourceheight $=1920$ \&initImg $=11$

Sportmax 2011 S/S. (n.d.). www.samsungdesign.net. Retrieved August 23, 2010, from http://www.samsungdesign.net/Collection/For Women/new_source.asp? sourcename $=38 \_242 \_6035 \_13 . j p g$ \&itemid $x=242 \&$ designerid $x=6035 \&$ seq $=13 \&$ an $=38 \&$ sourcewidth $=1197 \&$ sourceheight $=1800 \&$ initImg $=13$
Stella McCartney 2012 S/S. (n.d.). www.samsungdesign.net. Retrieved November 17, 2013, from http://www.samsungdesign.net/Collection/ For Women/new source. asp? sourcename $=$ 45_287_7987_17.jpg\&itemidx $=287 \&$ designeridx $=7987 \&$ seq $=17 \&$ a $\mathrm{n}=45$ \&sourcewidth $=690$ \&sourceheight $=1058$ \&initImg $=17$

Temperley london 2010 S/S. (n.d.). www.samsungdesign.net. Retrieved July 28, 2010, from http://www.samsungdesign.net/Collection/ForWomen/ new_source.asp?sourcename $=31 \_204 \_4132 \_2 . j p g \& i t e m i d x=204 \&$ designeridx $=4132 \&$ seq $=2 \&$ an $=31 \&$ sourcewidth $=900 \&$ sourceheight $=1$ 350\&initImg $=2$

Ter et Bantine 2011 S/S. (n.d.). www.samsungdesign.net. Retrieved August 23, 2010, from http://www.samsungdesign.net/Collection/ ForWomen/new source.asp ? sourcename $=38242$ 6036_13.jpg\&itemid $x=242 \&$ designerid $x=6036 \&$ seq $=13 \&$ an $=38$ \&sourcewidth $=1198 \&$ sourceheight $=1800$ \&initImg $=13$

Thakoon 2009 S/S. (n.d.). www.samsungdesign.net. Retrieved July 28, 2010, from http://www.samsungdesign.net/Collection/ForWomen/ new_source.asp? sourcename $=28 \_165 \_3171 \_4 . j p g \& i t e m i d x=165$ \&designeridx $=3171 \&$ seq $=4 \&$ an $=28 \&$ sourcewidth $=599 \&$ sourcehe ight $=900 \&$ initImg $=4$

Yang, Y. J., Oh, Y. O., \& Baek, E. Y. (2008). A study of geometric patterns in fashion collections. Bulletin of Korea Society of basic Design \& Art, 9(5), 305-315.

一見 輝, \& 八木 和子. (1999). 衣服. - 布地の 柄がかかる事典 [The pattern cyclopedia of clothings \& fabrics]. Japan: 日本實業出 版社

3.1 Phillip Lim 2009 S/S. (n.d.). www.samsungdesign.net. Retrieved July 28, 2010, from http://www.samsungdesign.net/Collection/ ForWomen/new_source.asp?sourcename $=28 \_165 \_3100 \_5 . j p g$ \&itemidx $=165 \&$ designeridx $=3100 \&$ seq $=5 \&$ an $=28 \&$ sourcewidth $=$ 599\&sourceheight=900\&initImg=5

(Received 11 January 2014; 1st Revised 16 January 2014; 2nd Revised 7 February 2014; 3rd Revised 14 February 2014; Accepted 25 February 2014)

Copyright $(\mathbb{C} 2014$ (by) the authors. This article is an open access article distributed under the terms and conditions of the Creative Commons Attribution license (http://creativecommons.org/licenses/by/3.0/), which permits unrestricted use, distribution, and reproduction in any medium, provided the original work is properly cited. 